\title{
Comparison of $0.5 \%$ Ropivacaine and $0.5 \%$ Bupivacaine in Supraclavicular Brachial Plexus Block For Upper Limb Surgery
}

\author{
Balwinderjit Singh ${ }^{1}$, lqbal Singh ${ }^{2}$ \\ ${ }^{1}$ Professor, Dept. of Anesthesia, PIMS, Jalandhar, Punjab-India, ${ }^{2}$ Ex-Professor and head, Dept. of Anesthesia, PIMS, Jalandhar, Punjab- India.
}

\section{Abstract}

Background: Brachial plexus blocks are commonly used for forearm and hand surgeries but due to adverse effect like cardiotoxicity there is lot of research going on to find more cardiostable agent.Ropivacaine is commonly tried now adays in place of bupivacaine for brachial plexus block. It is new amino amide local anaesthetic having less cardiac toxicity as compared to bupivacaine. The present study was performed at our Institute to compare the Clinical characteristics of $0.5 \%$ ropivacaine and $0.5 \%$ bupivacaine when used for supraclavicular brachial plexus block in forearm and hand surgeries. Subjects and Methods: In this prospective randomised study sixty patients of ASA-I and II scheduled for forearm and hand surgeries under supraclavicular brachial plexus block were randomly divided into two groups of thirty each. Group $\mathrm{R}$ received Ropivacaine $0.5 \% 20 \mathrm{ml}+10 \mathrm{ml}$ normal saline while Group B received Bupivacaine $0.5 \% 20 \mathrm{ml}+10 \mathrm{ml}$ normal saline. Mean pulse, blood pressure,onset of sensory and motor blockade, duration of analgesia, and side effecs of local anaesthetic used were noted in both the groups. Statistical analysis for clinical characterstics was done by student $t$ test and ANOVA was used to analyze hemodynamic variations between two groups. $p<0.05$ considered as significant and $p<0.01$ considered as highly significant. Results: Mean onset time of sensory blockade was $5.5 \pm 0.89$ mins in Group R and $6.5 \pm 0.65$ mins in Group B and motor blockade was $14.3 \pm 2.64$ mins in Group R and $12.4 \pm$ 2.06 mins in Group B. Mean duration of Analgesia in Group R was $432 \pm 18.2$ mins and in Group B was $492 \pm 20.3$ mins. There was no statistical significant difference in onset of sensory block, motor block and mean duration of analagesia between two groups ( $p>0.05$ ). Conclusion: Supraclavicular brachial plexus block using either 0.5\% Ropivacaine or $0.5 \%$ Bupivacaine have similar onset of sensory and motor blockade, duration of analgesia but due to potentially proven safety profile in the literatue compared to bupivacaine it may offer an advantage in modern clinical practice.

Keywords: Supraclavicular Block, Ropivacaine, Bupivacaine.

Corresponding Author: Dr. Balwinderjit Singh, Professor, Department Of Anaesthesia, PIMS Jalandhar, India

Received: February 2019

Accepted: March 2019

\section{Introduction}

Brachial plexus block provide a useful alternative to general anaesthesia for upper limb surgery. It results in obtaining ideal operating conditions by producing complete muscular relaxation and stable intra-operative hemodynamics. Regional Anaesthesia has a particular importance in the orthopedic surgery as compared to general anaesthesia due to better preservation of pharyngeal and laryngeal reflexes thus results in decreasing the risk of aspiration, ${ }^{[1]}$ decreased stress response in compromised patients and avoidance of difficult intubation. ${ }^{[2]}$ Regional Anaesthesia also results in better postoperative analgesia without undue sedation and facilitating early mobilization and discharge from the hospital.

Supra clavicular approach is commonly used for brachial plexus block because of its ease, reliability and high success rate. Moreover, this approach doesn't results in sparing of musculocutaneous or axillary nerves. Bupivacaine is a long acting local anaesthetic widely used in modern anaesthetic practice for more than thirty years but it results in severe cardiovascular and central nervous system toxicity. Hence there is a long term research is going on to find out new and safe agent for regional nerve block. Ropivacaine is a newer long acting amide local anaesthetic having improved safety profile as compared to bupivacaine. ${ }^{[3,4]}$ Ropivacaine has several other advantages namely to produce differential blockade with less motor blockade along with reduced cardiovascular and neurological toxicity we hypothesized that ropivacaine can be used in supraclavicular brachial plexus block instead of bupivacaine for upper limb surgery. To test this hypothesis we compared the clinical characterstics of ropivacaine with bupivacaine at our institute on patients posted for upper limb surgery requiring brachial plexus block.

\section{Aims and objectives:}

The primary aim of our study was to compare:

- The efficacy and clinical characteristics of ropivacaine $0.5 \%$ and bupivacaine $0.5 \%$ in supraclavicular brachial plexus block posted for forearm and hand surgery.

The secondary aim of our study was to see the effects of these drugs on haemodynamics and complications if any. 


\section{Subjects and Methods}

This study was conducted at Punjab Institute of Medical Sciences, Deptt. Of Anaesthesia, Jalandhar. The present study was done on 60 cases of either sex of ASA Class I or II between age group of 18 and 50 years, weighing between 40 to 60 kilograms, scheduled for upper limb surgeries under supraclavicular brachial plexus block after approval by institutional ethical committee. The study was also registered in clinical trial registry (CTRI/2018/03/012750)

A detailed history was taken and the patients were thoroughly examined on the previous day before the surgery. The procedure to be performed was explained to each patient.

\section{Exclusion criteria}

History of respiratory, cardiac, hepatic or renal disease, convulsions, pregnant women. Patient with the history of bleeding disorders, local infection at the site of injection, anomalies of neck and shoulder, fracture clavicle. Patients sensitive or allergic to lignocaine or bupivacaine.

Baseline BP and Pulse were measured in preanaesthesia room, ringer lactate infusion was started after peripheral intravenous cannulation. Patients were premedicated with Inj. Glycopyrollate $0.01 \mathrm{mg}$ per $\mathrm{Kg}$ of body weight intramuscularly half an hour before performing the block. Patients were shifted to operation theatre and monitor was connected. Inj. Midazolam $0.1 \mathrm{mg}$ per $\mathrm{Kg}$ of body weight was given intravenously before administering brachial plexus block. The patients were randomly and equally divided into two groups of thirty each by computer generated randomization. The group $\mathrm{R}$ (Ropivacaine) patients were given $20 \mathrm{ml}$ of $0.5 \%$ ropivacaine plus $10 \mathrm{ml}$ normal saline while Group B (Bupivacaine) patients received $20 \mathrm{ml}$ of $0.5 \%$ bupivacaine plus $10 \mathrm{ml}$ normal saline. After turning the head to opposite side, painting and draping of the supraclavicular region was done. The supraclavicular block was performed by classical approach with a 23 gauge $4 \mathrm{~cm}$ long needle. The neurovascular bundle was located with peripheral nerve locator and the drug was injected on obtaining parasthesia after negative aspiration for blood.

During Surgery pulse, systolic blood pressure, diastolic blood presure, oxygen saturation and ECG were monitered. Pulse, systolic blood presure, diastolic blood presure were recorded every 15 mins till the end of surgery. Oxygen was routinely administered via oxygen face mask at the rate of 4 litre per min. Maximum duration of all the surgeries were upto 90 mins.

\section{Sensory blockade was assessed by 3 point sensory score:}

- 0-Sharp pain on pinprick,

- 1-Touch sensation on pinprick,

- 2-Not even touch sensation on pinprick.

Onset of sensory blockade was taken as the time between injection and the complete ablation of pinprick test (sensory score-2). Duration of sensory block will be defined as the time from complete block to return of the parasthesia (sensory score-0). If a sensory score of 2 was not achieved even after 30 minutes or if there was sparing in any segment, the sensory analgesia was deemed to be not satisfactory and these patients were excluded from the study. Complications of brachial plexus block and side effects of local anaesthetics used were also noted.

Motor blockade was also assessed by a 3 point motor score described by Bromage:

- 0-Full flexion and full extension of elbow, wrist and fingers,

- 1-Ability to move fingers only,

- 2-Inability to move fingers.

Onset of motor blockade was considered as the time from performance of block to the time when a complete inability to move fingers (score-2) was achieved. Duration of motor blockade was considered as time from complete motor blockade to the restoration of full flexion and extension of elbow, wrist and fingers (score-0).

Postoperative analgesia was assessed by the 10 point visual analogue scale.

- $\quad$ No pain $=0$

- $\quad$ Mild pain = 1-3

- Moderate pain = 4-7

- Severe $=$ more than 7

Injection Diclofenac Sodium (1.5 mg/kg intramuscularly) was administered when VAS $>5$. Total duration of Analgesia (time from onset of sensory blockade to time when patient has a visual analogue scale of $>5$ ) was also recorded between two groups.

The results were expressed as mean \pm SD. Statistical analysis for clinical characterstics was done by student t test. Mann witney test was used to analyse sex variation and ANOVA was used to analyze hemodynamic variations between two groups. $\quad \mathrm{p}<0.05$ considered as significant and $\mathrm{p}<0.01$ considered as highly significant

\section{Results}

There was no statistical significant difference in age, weight $\&$ sex distribution between two groups

Onset and duration of Sensory and Motor Block

As [Table 1] shows, mean duration of onset of sensory block in ropivacaine group was $5.5 \pm 0.89$ mins and in bupivacaine group was $6.5 \pm 0.65$ mins. Mean duration of onset of motor block in ropivacaine group was $14.3 \pm 2.64 \mathrm{mins}$ and in bupivacaine group was12.4 \pm 2.06 . but on inter group comparison there was no statistical significant difference in Onset of sensory block, Onset of motor block between two Groups ( $\mathrm{p}>0.05)$.

Table 1: Onse of Sensory and Motor Block in two Groups (min) $($ Mean \pm SD)

\begin{tabular}{|l|l|l|l|}
\hline Variable & $\begin{array}{l}\text { Group R } \\
\text { (Ropivacaine) }\end{array}$ & $\begin{array}{l}\text { Group } \\
\text { (Bupivacaine) }\end{array}$ & p-value \\
\hline Sensory Block & $5.5 \pm 0.89$ & $6.5 \pm 0.65$ & $>0.05$ \\
\hline Motor Block & $14.3 \pm 2.64$ & $12.4 \pm 2.06$ & $>0.05$ \\
\hline
\end{tabular}

\section{Intra-operative Parameters:}

There was no statistical significant difference in intraoperative parameters namely pulse, systolic blood pressure and diastolic blood pressure between two groups $(\mathrm{p}>0.05)$.

\section{Duration of Analgesia:}


As [Figure 1] shows, duration of Analgesia in Ropivacaine Group was $420 \pm 18.2$ mins and in Bupivacaine group was $462 \pm 20.3$ mins, but data was statistically insignificant $(\mathrm{p}>0.05)$.

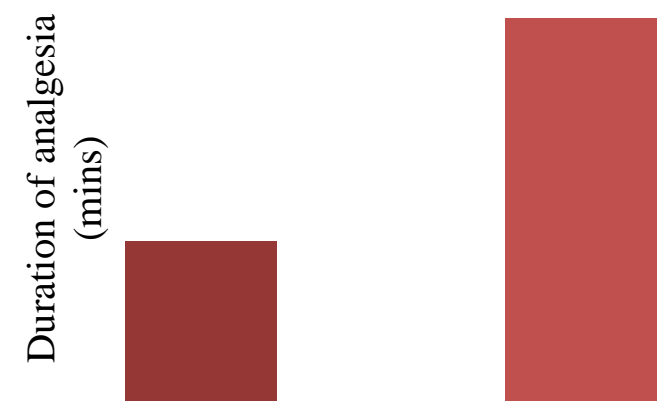

Figure 1: Duration of Analgesia between two Groups (mins)

\section{Comparison of Complications:}

In our study, $13.3 \%$ of patients have incidence of nausea and $3.3 \%$ have Horner's Syndrome in Ropivacaine group as compared to patients having $20 \%$ incidence of nausea and $6.6 \%$ Horner's Syndrome in Bupivacaine group ( $p>0.05$ ).

Table 2: Comparison of Complications between two Groups.

\begin{tabular}{|l|l|l|}
\hline Complication & Group R (Ropivacaine) & $\begin{array}{l}\text { Group } \\
\text { (Bupivacaine) }\end{array}$ \\
\hline Nausea & $4(13.3 \%)$ & $6(20 \%)$ \\
\hline $\begin{array}{l}\text { Horner's } \\
\text { Syndrome }\end{array}$ & $1(3.3 \%)$ & $2(6.6 \%)$ \\
\hline
\end{tabular}

\section{Discussion}

In our prospective randomised clinically study we compared 30 patients (Group R- $20 \mathrm{ml}$ of $0.5 \%$ ropivacaine with $10 \mathrm{ml}$ normal saline) with 30 patients of (Group B- $20 \mathrm{ml}$ of $0.5 \%$ bupivacaine with $10 \mathrm{ml}$ normal saline). There was no statistical significant difference regarding age, weight and sex distribution between two groups .The onset of Sensory Block in Group R was 5.5 mins while in Group B was 6.5 mins and the onset of Motor Blockade in Group R was 14..3 mins and in Group B was 12.4 mins. Although Sensory onset was faster in Group R than in Group B, Motor onset was faster in Group B than in Group R but there was no statistical significant difference between two groups $(p>0.05)$.

\footnotetext{
Similar observations were found by Tomoki Nishiyama(5) as follows:

Sensory and motor onset in ropivacaine group was $11 \& 14$ mins and in bupivacaine group was $10 \& 11$ mins respectively but the data was statistically insignificant ( $>0.005)$.

Himat Vaghadia et al, ${ }^{[6]}$ Stephen M Klein et al, ${ }^{[3]}$ also found in their study that there was no statistical significant difference between the onset of Sensory block and motor block among ropivacaine and bupivacaine group ( $p>0.05)$. We found that total duration of analgesia in Group $R$ was 7.0 hours $(420 \pm 18.2$ mins) while in Group B was 7.6 hours $(460 \pm 20.3$ mins $)$ [Figure 1]. Statistically there was no significant difference between two groups $(\mathrm{p}>0.05)$.
}

Similar observations were found by Stephen M Klein et al and Vaghadia et al, ${ }^{[3,6]}$ in their study regarding total duration of analgesia and showed no significant difference between ropivacaine and bupivacaine group for brachial plexus block $(\mathrm{p}>0.05)$.

There was no statistical significant difference of variation in intra-operative pulse, SBP, DBP between two Groups. Rosemary et al, ${ }^{[9]}$ also didn't observe significant variation in mean, heart rate, systolic blood pressure between $0.5 \%$ Ropivacaine and $0.5 \%$ Bupivacaine at different time intervals.

It is theoretically proved that Ropivacaine has lessor potential for cardiotoxicity as compared to Bupivacaine. In isolated rabbit purkinje's fiber muscle preparation effect of Ropivacaine on the transmembrane action potential was generally less than that of Bupivacaine. ${ }^{[10]}$ Intact animal studies have also demonstrated that Ropivacaine having lesser arrythmogenic potential than Bupivacaine. ${ }^{[11]}$ Scott et $\mathrm{al},{ }^{[12]}$ also demonstrated depression of conduction on ECG and contractility (M-mode ECHO) at lower doses of Bupivacaine as compared to Ropivacaine.

So in view of lesser potential to toxicity in case of Ropivacaine in animal model it may be useful option in Brachial plexus block and other peripheral nerve blocks where risk of intravascular injection is very high.

\section{Conclusion}

We can conclude that ropivacaine can produce equal and comparable supraclavicular brachial plexus blockade to bupivacaine with reduced risk of complications.

\section{References}

1. Mckenzie $\mathrm{Pj}$, Loach AB.local anaesthesia for orthopedic surgery. Br J Anaesth.1986;58:779-89.

2. Col. K C Kothari Regional Anaesthesia Techniques for Orthopedic Surgery; MJAFI 2008; 64:108-10.

3. Klein SM, Greengrass RA, Steele SM. A comparison of $0.5 \%$ bupivacaine, $0.5 \%$ ropivacaine and $0.75 \%$ ropivacaine for interscalene brachial plexus block. Anesth Analg 1998; 87:1316-9.

4. Healy TE, Knight P.R., Wylie and Churchill-Davidson's A Practice of Anaesthesia: 7th edition.

5. Tomoki Nishiyama. Comparison of the motor and sensory block by ropivacaine and bupivacaine in combination with lidocaine in interscalene block. Med Art. 2012 Oct; 66(5): 315-317.

6. Vaghadia H, Chan V, GanapathyS,Lui A, McKenna J, Zimmer K. A multicentre trial of Ropivacaine $7.5 \mathrm{mg} / \mathrm{ml} \mathrm{V/s} \mathrm{Bupivacaine} 5 \mathrm{mg} / \mathrm{ml}$ for supraclavicular brachial plexus anaesthesia.Can J Anaesth 1999;46(10):946-51.

7. Hickey R, Candido KD, Rammurthy S, Winnie AP, Blanchard J, Raza SM, Hoffman J, Durrani Z, Masters RW: Brachial plexus block with a new local anaesthetic 0.5\% ropivacaine. Can J Anaesth 1990; 37:732738 .

8. Eroglu A, Uzunlar H, Sener M, Akinturk Y, Erciyes N. A clinical comparison of equal concentration of volume of Ropivacaine and Bupivacaine for interscalene brachial plexus anaesthesia and analgesia in shoulder surgery. Reg Anaesth and Pain Med 2004NovDec;29(6):539-43.

9. Hickey R, Rowley CL, Candido KD, Hoffman J, Ramamurthy S, Winnie AP, A comparative study of $0.25 \%$ ropivacaine and $0.25 \%$ bupivacaine for brachial plexus block. Anesth Analg. 1992; 75: 602606.

10. Moller R, Covino BG. Cardiac electrophysiologic properties of bupivacaine and lidocaine compared with those of ropivacaine, a new amide local anaesthetic. Anaesthesiology 1990; 72:322- 329.

11. Reiz S, Haggemark S, Johansson G, Nath S: Cardiotoxicity of 
ropivacaine- a new amide local anaesthetic agent. Acta Anesthesiol Scand $1989 ; 33: 93-98$
12. Scott DB, Lee A, Fagan D, et al. Acute toxicity of ropivacaine compared with that of bupivacaine. Anesth Analg 1989;69:563-569.

Copyright: (ㅇ the author(s), publisher. Academia Anesthesiologica International is an Official Publication of "Society for Health Care \& Research Development". It is an open-access article distributed under the terms of the Creative Commons Attribution Non-Commercial License, which permits unrestricted non-commercial use, distribution, and reproduction in any medium, provided the original work is properly cited.

How to cite this article: Singh B, Singh I. Comparison of 0.5\% Ropivacaine and 0.5\% Bupivacaine in Supraclavicular Brachial Plexus Block For Upper Limb Surgery. Acad. Anesthesiol. Int. 2019;4(1):29-32.

DOI: dx.doi.org/10.21276/aan.2019.4.1.7

Source of Support: Nil, Conflict of Interest: None declared. 